Original Article

\title{
DRUG UTILIZATION BASED ADRS MONITORING OF ANTIHYPERTENSIVE AGENTS PRESCRIBED IN AL-QUWAYIYAH GENERAL HOSPITAL, SAUDI ARABIA
}

\author{
MD SALAHUDDIN ANSARI ${ }^{*}{ }^{*}$, FAISAL AL-OTAIBI ${ }^{2}$ \\ ${ }^{1}$ Lecturer, College of Pharmacy Al Dawadmi, Shaqra University, Saudi Arabia, ${ }^{2}$ College of Pharmacy Al Dawadmi, Shaqra University, Saudi Arabia \\ Email: msdpharma@gmail.com
}

Received: 21 Sep 2017 Revised and Accepted: 11 Jan 2018

\begin{abstract}
Objective: To monitor drug utilization based adverse drug reactions (ADRs) of antihypertensive agents prescribed in Al-Quwayiyah general hospital, Saudi Arabia.

Methods: An open, non-comparative, observational study was conducted on hypertensive patients attending the medicine outpatient department of Al-Quwayyah general hospital, Al-Quwayyah, Saudi arabia. Data were collected by conducting patient interviews. Data were captured for adverse drug reaction monitoring based on Narinjo scale and WHO format.

Results: 25 ADRs were observed out of 212 hypertensive patients. Incidence was found to be higher in patients more than 40 y age, and females experienced more ADRs $(n=16,7.54 \%)$ than males, $9(4.62 \%)$. Combination therapy was associated with more number of ADRs (64.0\%) as against monotherapy (36.0\%). Calcium channel blockers were found to be the most frequently associated drugs with ADRs ( $\mathrm{n}=8$ ), followed by diuretics ( $\mathrm{n}$ $=6)$, and $\beta$-blockers $(n=5)$. Among individual drugs, amlodipine was found to be the commonest drug associated with ADRs ( $\mathrm{n}=8$ ), followed by torasemide $(n=4)$. ADRs associated with the central nervous system was found to be the most frequent (48.0\%) followed by musculoskeletal
\end{abstract} complaints (20.0\%) and respiratory system disorders (16.0\%).

Conclusion: ADRs were experienced by taking the antihypertensive drugs prescribed in Al-Quwayyah general hospital, Saudi arabia. The findings would be useful for physicians in rational prescribing. Calcium channel blockers were found to be the most frequently associated drugs with ADRs.

Keywords: Adverse drug reactions (ADRs), World health organization (WHO), Drug utilization, Antihypertensive drugs

(C) 2018 The Authors. Published by Innovare Academic Sciences Pvt Ltd. This is an open access article under the CC BY license (http://creativecommons.org/licenses/by/4.0/) DOI: http://dx.doi.org/10.22159/ijpps.2018v10i3.15296

\section{INTRODUCTION}

Hypertension is the most common cardiovascular disease and it has been defined arbitrarily as a systolic blood pressure greater than 140 $\mathrm{mm} \mathrm{Hg}$ or a diastolic pressure greater than $90 \mathrm{~mm} \mathrm{Hg}$ [1]. The world health organization (WHO) has estimated one in every eight death globally due to hypertension. It's an increase in hypertension approximately $1 / 4$ of the Saudi Arabia population and has become an important health problem affecting a large number of Saudi people [2].

In $90-95 \%$ of cases of hypertension, there is no underlying medical illness to cause an increase in B. P. This is termed essential hypertension. The etiology of essential hypertension tends to run in families, with hypertension being twice as common in families who have a hypertensive patient [3].

Improvement in patient's awareness, compliance and physicians adherence to treatment guidelines of various pharmacological approach exist for the control blood pressure [4]. It's a global challenge to control hypertension, requires mutual co-operation among multiple constituencies, including patients, health-care professionals, industry, media, health-care educators, health planners and governments. The health-care team needs to take action locally with patients to manage blood pressure treatments [5].

Adverse drug events (ADEs) are described as any unwanted events resulting from therapy; it may be physical, physiological, mental and loss of function of any organ [6]. As per WHO ADR is "A response to a drug that is untoward and unintended events occur at doses level normally used in human for the prophylaxis, diagnosis, treatment of disease and for modification of physiological function" [7]. Hospital Pharmacists of an American Society defined that a countable ADR is any unpredicted, unintended, undesired or unexcessive response to a drug, that requires discontinuation, changing, modifying the dose of a drug, necessary to get hospitalized, prolonged to stay in touch with healthcare facility, supportive treatment required, complicate the diagnosis, badly affects prognosis or results in temporary or permanent harm, disability or death [8]. Food Drug and Administration defines a severe adverse reaction as one in which the patient may be dying, or life-threatening consequences, hospitalization, disabilities, congenital abnormalities or need intervention to progress permanent impairment or damage [9].

ADRs cause many leading morbidity and mortality, Monitoring are more important in case of chronic disease as hypertension. Hypertension is an asymptomatic disorder and requires long-term therapy predisposing to ADEs [10]. The use of antihypertensive drugs related to the development of ADRs to about 1/4th of the patients in the OPD of cardiovascular unit [11]. With an impairment of the quality of life and an increase in healthcare costs, monitoring of ADRs through pharmacovigilance is useful to improve the safety of each patient [12]. The objective of present study was to focus on ADRs of antihypertensive drugs in the outpatients attending the OPD, Department of Medicine in general hospital AlQuwayyah, Saudi arabia.

\section{MATERIALS AND METHODS}

\section{Methodology}

Study design: Prospective, observational analysis of Adverse drugs reactions Patterns in patients with established hypertension. All the observations were recorded in special designed documentation form.

Study site: The Study was carried out in the OPD of cardiovascular diseases in the college of Applied medical science Al-Quwayyah General Hospital, Al-Quwayyah, Saudi Arabia.

Duration of study: The study was carried out during the period of December 2011 to May 2012 (6 mo).

Subject demographics: Study was conducted on 212 eligible patients at Al-Quwayyah General Hospital who were willing to participate. Patients $(n=25)$ presenting with ADR were observed for 
changes in physical and biochemical parameters based on pathological lab reports.

Material used: Adverse Drug Reaction Monitoring form, Naranjo's probability scale and WHO form.

Inclusion criteria: All hypertensive patients irrespective of age and sex visiting Medicine OPD in General Hospital were included in the study Patients treated with at least one antihypertensive agent.

\section{Exclusion criteria}

- Patients who were not treated with antihypertensive agents

- Drug addicts

- All the mentally retarded and unconscious patients

\section{Sources of data}

- Physician prescribing records.

- Patient's medication profile

\section{Data collection}

Information on age, gender, drugs prescribed and ADR information were recorded on special design form in Medicine OPD by conducting a patient interview after their informed consent was obtained. All the data were kept confidential.

\section{Sample collection}

The hypertensive patients presenting with ADRs were called to the pathology sample collection centre and their fasting venous blood sample $(5 \mathrm{ml})$ was collected by a trained laboratory technician to established ADRs.

\section{RESULTS}

\section{Gender distribution of the subjects}

During the study period, a total of 212 hypertensive patients visited Al-Quwayyah general hospital. Among the 212 hypertensive patients, 115 (54.2\%) were males and 97 (45.8\%) were females indicating that hypertension is slightly more prevalent in the female gender.

\section{Monitoring of ADRs}

\section{Gender distribution of ADRs in hypertensive patients}

A total of 25 ADRs were observed in 212 hypertensive patients in which 115 male and 97 female were taken for study. In which it was found that females experienced more ADRs $(n=16)$ than males $(n=9)$.

\section{Distribution of ADRs among various age groups}

The most vulnerable age group was 41-50 y with respect to ADRs $(n=8)$ followed by 71-80 y $(n=5), 51-60$ y and 61-70 $(n=4$ each), 31$40 \mathrm{y}$ and $21-30 \mathrm{y}(\mathrm{n}=2$ each).

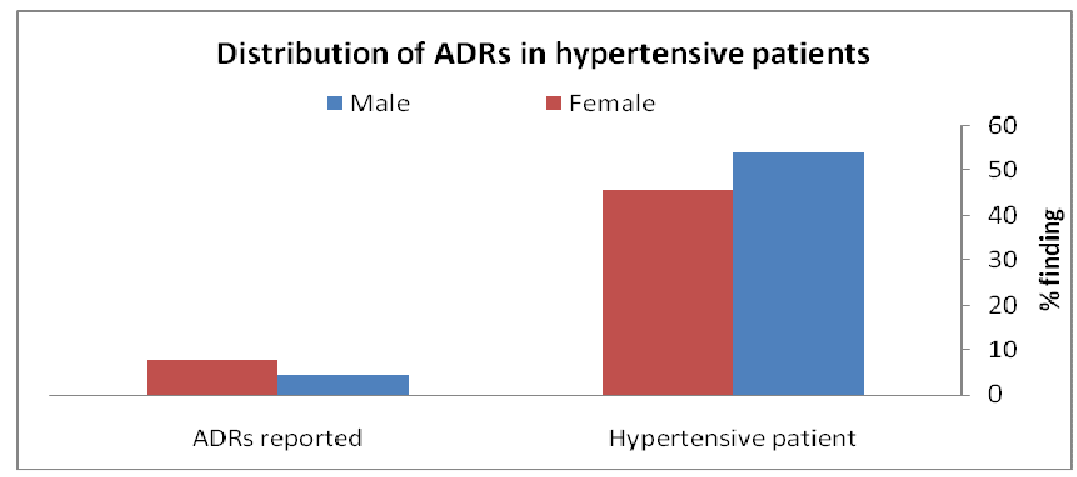

Fig. 1: Gender wise distribution of ADRs

\section{ADRs in mono vs. combination therapy}

Combination therapy was associated with more number of ADRs $(64.0 \%)$ as against monotherapy (36.0\%).

\section{ADRs and therapeutic class of suspected medication}

The details of ADRs associated with the antihypertensive medicines observed in our study are shown in table Calcium channel blocker was found to be the commonest therapeutic class associated with
ADRs $(n=8)$, followed by diuretics $(n=6), \beta$-blockers $(n=5)$, ACE inhibitors $(n=2)$ and Angiotensin receptor blockers $(n=4)$.

\section{Classification of ADRs on the basis of severity}

The ADRs observed in our study mostly in the class of mild ( $\mathrm{n}=$ $15,60 \%$ ), which were well tolerated by the patients for example, Nausea, headache, dizziness etc. followed by moderate $(n=10$, $40 \%$ ) as for example sleeping disturbances, depression etc. None of the ADRs was categorized as severe.

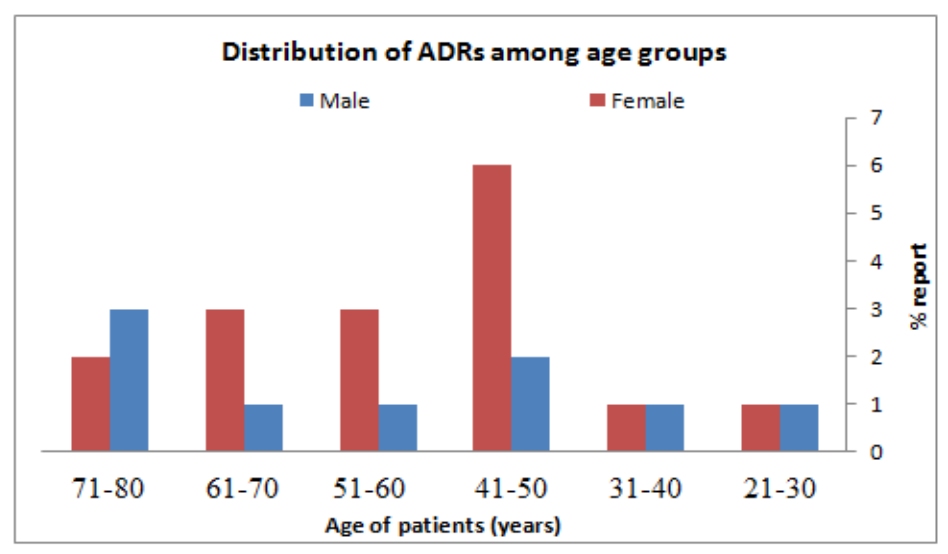

Fig. 2: ADRs distribution in various age groups 


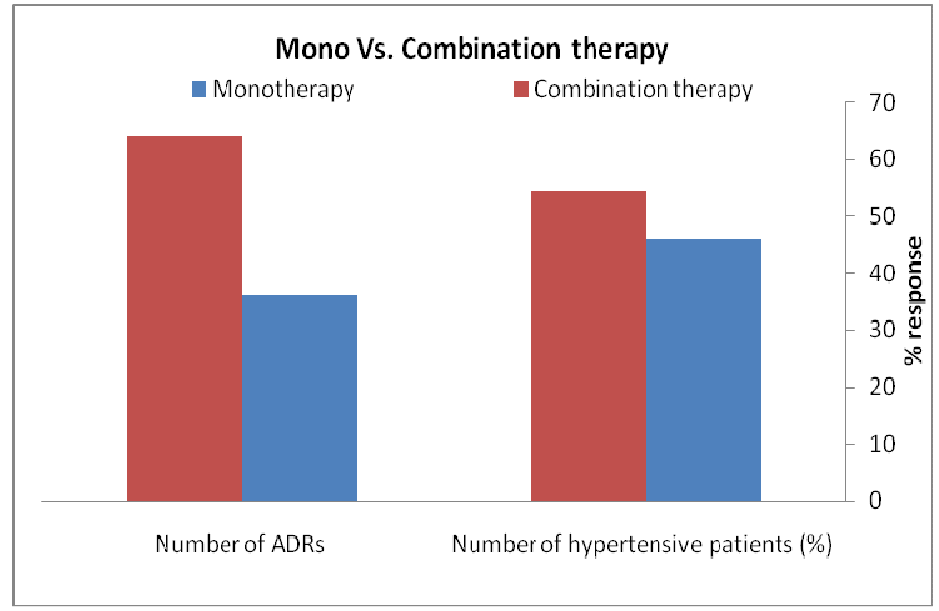

Fig. 3: Distribution of ADRs among different antihypertensive patient

Table 1: Types of ADRs shown by different antihypertensive medicine

\begin{tabular}{|c|c|c|c|}
\hline Suspected drugs & ADRs experienced & No. of ADRs (\%) & Interventions \\
\hline \multicolumn{4}{|c|}{ Calcium channel blockers } \\
\hline \multirow[t]{5}{*}{ Amlodipine } & Ankle edema & 02 & Dechallenge \\
\hline & Abdominal pain & 02 & Symptomatic treatment \\
\hline & Sedation & 02 & Symptomatic treatment \\
\hline & Pedal edema & 01 & Symptomatic treatment \\
\hline & Back pain & 01 & Symptomatic treatment \\
\hline Total & & $08(32.0 \%)$ & \\
\hline \multicolumn{4}{|l|}{ Diuretics } \\
\hline \multirow[t]{3}{*}{ Torasemide } & Fatigue & 01 & Symptomatic treatment \\
\hline & Visual impairment & 01 & Dechallenge \\
\hline & Dizziness & 02 & No change in treatment \\
\hline Total & & $04(16.0 \%)$ & \\
\hline \multirow[t]{2}{*}{ Amiloride } & Dizziness & 01 & No change in treatment \\
\hline & Loss of appetite & 01 & Symptomatic treatment \\
\hline Total & & $02(8.0 \%)$ & \\
\hline Grand total & & $06(24.00 \%)$ & \\
\hline \multicolumn{4}{|l|}{ Beta-blockers } \\
\hline Atenolol & Bradycardia & 02 & No change in treatment \\
\hline Metoprolol & Headache & 01 & No change in treatment \\
\hline \multirow[t]{2}{*}{ Propranolol } & Insomnia & 01 & Dechallenge \\
\hline & Depression & 01 & \\
\hline Grand total & & $05(20.0 \%)$ & \\
\hline \multicolumn{4}{|l|}{ ACE inhibitors } \\
\hline Ramipril & Dry cough & 02 & Dechallenge \\
\hline Total & & $02(8.0 \%)$ & \\
\hline \multicolumn{4}{|c|}{ Angiotensine receptor blockers } \\
\hline Telmisartan & Dizziness & 01 & Dechallenge \\
\hline Losartan & Dizziness & 02 & No change in treatment \\
\hline Olmesartan & Dizziness & 01 & No change in treatment \\
\hline Grand total & & $04(16.0 \%)$ & \\
\hline
\end{tabular}

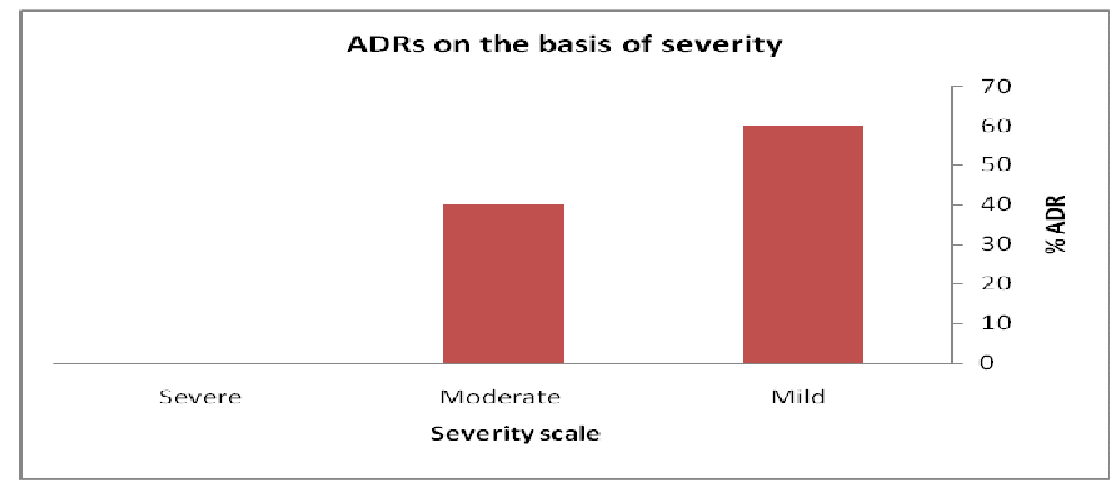

Fig. 4: Severity of ADRs 


\section{Organs/systems affected due to medicines}

ADRs associated with CNS ( $\mathrm{n}=12,48 \%)$ were found in majority of patients e. g. dizziness, headache, depression etc. followed by musculoskeletal ( $\mathrm{n}=5,20 \%$ ) problems example back pain, fatigue. Similarly respiratory related complaint like cough $(n=4,16 \%)$, gastrointestinal disorders $(\mathrm{n}=3,12 \%)$ abdominal pain, anorexia and ophthalmic dry eye symptoms $(n=1,4 \%)$.

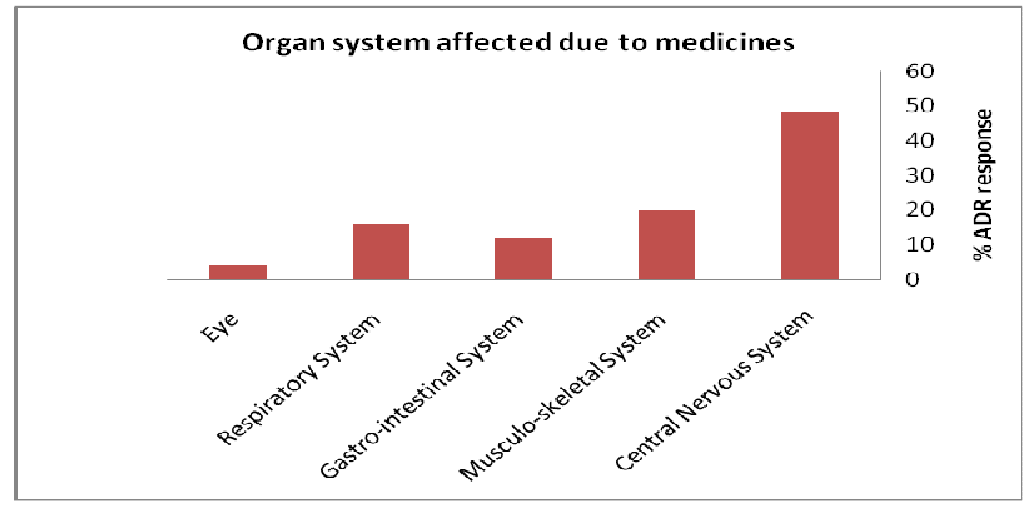

Fig. 5: Organs system affects due to medicines

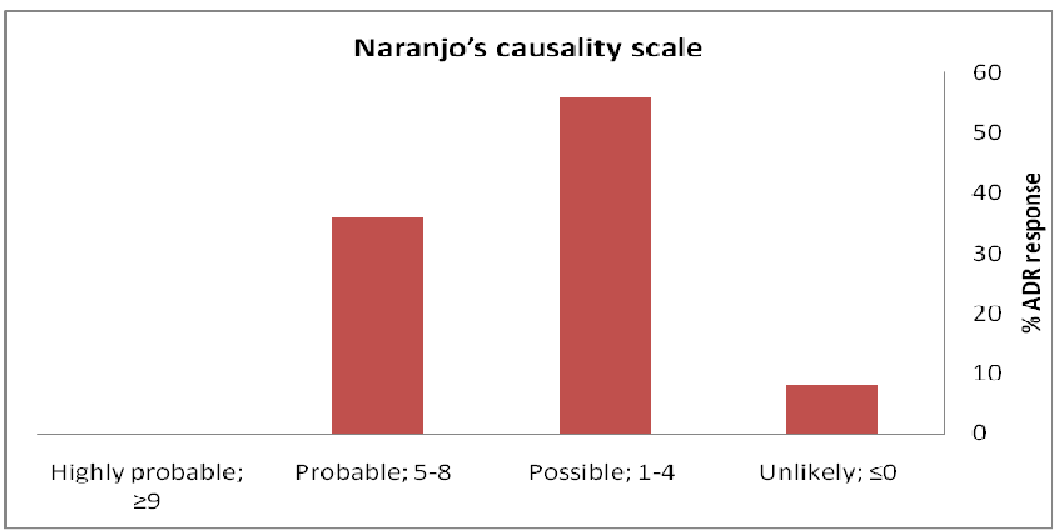

Fig. 6: Classification of ADRs on the basis of Naranjo's causality scale

\section{Classification of ADRs on the basis of naranjo's causality scale}

More than half (56\%) of the reported ADRs were classified as possible, $36 \%$ as probable and $8 \%$ as unlikely on Naranjo's probability scale.

\section{DISCUSSION}

The details of our study indicated that female-dominated over males which were similarly reported in [13]. This might be because of sedentary lifestyle which makes them more susceptible to the pharmacological adverse effects of dosages forms and increases the chance of ADRs. The older patients experienced more adverse drug reaction i.e., more than 40 years with compare to younger ones i.e., less than 40 years. The root cause behind this is compromised organ functioning, depressed of basal metabolic rate, simultaneous other disease conditions and multiple drug therapy might be the main cause of ADRs, as there is need to opt multiple drug therapy, ultimately result of that higher incidence of ADRs in older patients reported [14].

ADRs showed more in case of the multiple therapies as compared to monotherapy. Several observational studies on risk factors for ADRs had shown that patients on multiple therapies were more predisposed to develop ADRs as compared to patients on monotherapy observed [15]. Multiple drug therapy increases the probability of ADRs because drug-drug interactions.

Among individual Calcium channel blockers were showed the major ADRs. Amlodipine drug was found to be the frequent drug associated with ADRs $[16,17]$. The most common ADRs with amlodipine were: abdominal pain, ankle edema, sedation, pedal edema, and back pain. Edema has been reported as the most common problem with amlodipine [18]. Torasemide used as a diuretic was associated with fatigue, visual impairment and dizziness types of the ADRs. Dizziness and headache reported as common side effects with diuretics. These side effects may be related to the fluid retention or electrolytes imbalance caused by these drugs. Ramipril showed a dry cough most often ADRs in our study. This is in co-relation of earlier study is that almost majority of patients experienced dry cough on using ACE inhibitors the same finding was observed by [19].

The ADRs showed on different types organ/system of the body were evaluated and observed that symptoms reported by the patients who experienced ADRs. According to our study, the most prevalence systems associated with ADRs were the central nervous system (CNS) followed by musculoskeletal system. The similar finding was reported by [20].

\section{CONCLUSION}

Present study was designed and conducted in Saudi government hospital to monitor ADRs of antihypertensive medicines. The study finding showed that male was more prone to hypertension compared to female in mid-age group whereas females' patients were found more prone to ADRs in the age group of $40 \mathrm{y}$. The combination therapy showed more ADRs cases compare to monotherapy treatment scheme. The maximum ADRs observed with calcium channel blockers, followed by diuretics, $\beta$-blockers, angiotensin receptor blockers and ACE inhibitors. Amlodipine was showed to be the commonest drug associated ADRs. In most of the 
ADRs cases observed in this study were mild and well tolerated by the patients. The main limitation of the present study was the limited sampled size and short duration study. It's our recommendation that more exhaustive study of special groups like pregnant women and paediatrics need to be included in the further study.

\section{ACKNOWLEDGEMENT}

We thank to the Clinician (Doctors), laboratory staff and Pharmacist of Al-Quwayyah general hospital and also Administration, faculty member, Technician and non-teaching staff of college of Pharmacy, Shaqra University for their enthusiastic co-operation. It's our special thanks to dean college of Applied medical science Al-Quwayyah Dr. Ibrahim Ghanim for his continued encouragement. In last we encourage and thanks to project coordinator of research study and students of college of pharmacy Al Dawdmi for their full cooperation and support. We would like to say here that there was no any financial support by any agency.

\section{AUTHORS CONTRIBUTIONS}

All the author have contributed equally

\section{CONFLICT OF INTERESTS}

\section{Declared none}

\section{REFERENCES}

1. Aqil M, Imam F, Hussain A, Alam MS, Kapur P, Pillai KK. A pharmacovigilance study for monitoring adverse drug reactions with antihypertensive agents at a South Delhi hospital. Int J Pharm Pract 2006;14:311-3.

2. Al-Turki KA, Al-Baghli NA, Al-Ghamdi AJ, EL-Zubaier AG. Hypertension in the eastern province of saudi arabia: results of a screening campaign. J Family Community Med 2008;15:95-101.

3. Arulmani R, Rajendran SD, Suresh B. Adverse drug reaction monitoring in a secondary care hospital in South India. Br J Clin Pharmacol 2008;65:210-6.

4. Brown MT, Bussell JK. Medication adherence: WHO cares? Mayo Clin Proc 2011;86:304-14.

5. Bakris G, Hill M, Mancia G. Achieving blood pressure goals globally: five core actions for health-care professionals. A worldwide call to action. J Hum Hypertens 2008;22:63-70.

6. Hughes RG, Blegen MA. Medication administration safetypatient safety and quality. Agency for healthcare research and quality (US); 2008. p. 2.

7. Chobanian AV, Bakris GL, Black HR, Cushman WC, Green LA. The seventh report of the joint national committee on prevention, detection, evaluation, and treatment of high blood pressure: the JNC 7 report. JAMA 2003;289:2560-72.

8. Palanisamy S, Kumaran KS, Rajasekaran A. A study on assessment, monitoring and reporting of adverse drug reactions in Indian hospital. Asian J Pharm Clin Res 2011;4:112-6.

9. Gholami K, Ziaie S, Shalviri G. Adverse drug reactions induced by cardiovascular drugs in outpatients. Pharm Pract 2008;6:51-5.

10. Adepu R, Madhu S. Influence of post-discharge counselling on health outcomes in diabetic and hypertensive patients. Asian J Pharm Clin Res 2011;4:28-33.

11. Guidelines Committee. European society of hypertensioneuropean society of cardiology guidelines for the management of arterial hypertension. J Hypertens 2003;21:1011-53.

12. Jha N, Bajracharya O, Namgyal T. Prevalence of adverse drug reactions with commonly prescribed drugs in different hospitals of Kathmandu valley. Kathmandu Univ Med J 2007;5:504-10.

13. Regitz Zagrosek V. Sex and gender differences in health-science and society series on sex and science. Eur Mol Biol Organization Repots 2012;7:596-603.

14. Khurshid F, Aqil M, Alam MS, Kapur P. Monitoring of adverse drug reactions associated with antihypertensive medicines at a university teaching hospital in New Delhi. DARU J Pharm Sci 2012;20:34.

15. Alomar MJ. Factors affecting the development of adverse drug reactions. Saudi Pharma J 2014;22:83-94.

16. Woo KS, Nicholls MG. High prevalence of a persistent cough with angiotensin-converting enzyme inhibitors in Chinese. $\mathrm{Br} \mathrm{J}$ Clin Pharmacol 1995;40:141-4.

17. Bramlage $P$, Thoenes $M$, Kirch $W$, Lenfant C. Clinical practice and recent recommendations in hypertension managementreporting a gap in a global survey of 1259 primary care physicians in 17 countries. Curr Med Res Opin 2007; 23:783-91.

18. Bakris G, Hill M, Mancia G, Steyn K, Black HR, Pickering T, et al. Achieving blood pressure goals globally. five core actions for health-care professionals. A worldwide call to action. J Human Hypertens 2008;22:63-70.

19. Ahmad SR. Adverse drug event monitoring at the food and drug administration. J Gen Intern Med 2003;18:57-60.

20. Mohebbi N, Shalviri G, Salarifar M, Salamzadeh J, Gholami K. Adverse drug reactions induced by cardiovascular drugs in cardiovascular care unit patients. Pharmacoepidemiol Drug Safety 2010;19:889-94. 